\title{
NILAI AWAL PADA METODE NEWTON-RAPHSON YANG DIMODIFIKASI DALAM PENENTUAN AKAR PERSAMAAN
}

\author{
Patrisius Batarius \\ TeknikInformatika, Universitas Katolik Widya Mandira Kupang \\ patrisbatarius@gmail.com
}

\begin{abstract}
Abstrak: Penentuan akar suatu persamaan berarti membuat persamaan tersebut sama dengan nol $\mathrm{f}(\mathrm{x})=0$. Beberapa metode numerik bisa digunakan untuk menentukan akar persamaan yang bentuknya sangat kompleks. Akan tetapi untuk akar ganda, beberapa metode numerik seperti metode bisection, metode regulafalsi, metode Newton-Raphson, metode Secant memiliki kesulitan. Penelitian ini bertujuan untuk mengetahui pengaruh penentuan nilai awal pada metode Newton-Raphson yang dimodifikasi dalam mementukan akar persamaan yang memiliki akar ganda. Simulasi dilakukan pada persamaan yang memiliki 1 akar tunggal dan 2 akar ganda atau lebih. Dengan metode Newton-Raphson nilai awal yang dipilih dekat dengan akar tunggal maka akarnya terletak pada sekitar atau sama dengan akar tunggal. Namun dengan metode Newton-Raphson yang dimodifikasi pemilihan nilai awal lebih dekat dengan akar tunggal, nilai akar yang dihasilkan menunjuk pada akar ganda..
\end{abstract}

Kata Kunci: Metode Newton-Raphson; Metode Newton-Raphson Modifikasi; akar persamaan; akar ganda.

\section{Pendahuluan}

Persamaan matematika di bidang teknik sering dijumpai. Diantaranaya ada yang berbentuk persamaan linear, ada yang berbentuk eksponensial, ada yang berbentuk polynomial. Ada yang bersifat sederhana ada pula yang bentuknya kompleks. Mencari akar persamaanpersamaan tersebut berarti membuat persamaan itu menjadi nol, $\mathrm{f}(\mathrm{x})=0$. Tidak semua persamaan yang ada bisa diselesaikan dengan mudah menggunakan teori matematika. Pendekatan metode numerik sering digunakan untuk menyelesaiakn persamaan-persamaan yang kompleks. Persamaan matematika yang kompleks diselesaikan dengan metode numerik.

Akar suatu persamaan, tidak selamanya tunggal. Persamaanpersamaan matematika sering memiliki akar ganda. Beberapa metode numeric yang sering digunakan seperti metode Bisection, metode Newton-Raphson, metode Secant, metode regulaflasi, mengalami kesulitan dalam menentukan akar ganda. Terkadang hasil dari metodemetode yang disebutkan terjadi divergensi. Hasil akar yang dicari tidak ditemukan.

Salah satu metode Numerik yang sering digunakan untuk menentukan akar persamaan adalah metode NewtonRaphson. Metode Newton-Raphson memiliki kelebihan dan lebih cepat konvergensi dalam menentukan akar persamaan. Namun untuk persamaan yang memiliki akar ganda, metode Newton-Raphsonperlu dilakukan modifikasi. Metode Newton-Raphson hasil modifikasi sering disebut Metode Newton-Raphosn yang dimodifikasi. Namun demikian penentuan nilai awal mempengaruhi jumlah iterasi dan kecepatan konvergensi metode NewtonRaphson yang dimodifikasi

Penentuan nilai awal metode Newton-Raphson dan metode NewtonRaphosn yang dimodifikasi mempengaruhi kecepatan konvergensi 
penentuan akar suatu persamaan. Metode Newton-Raphson yang dimodifikasi bisa digunakan untuk mencari akar persamaan baik yang akar tunggal maupun yang akar ganda. Pencarian akar tunggal dengan metode Newton-Raphson lebih cepat konvergensi jika dibandingkan dengan metode Newton-Raphson yang dimodifikasi. Nilai awal metode NewtonRaphson yang dimodifikasi, sangat berpengaruh terhadap pencarian akar bagi persamaan yang memiliki lebih dari satu akar tunggal dan akar ganda. Penelitian ini bertujuan untuk mengetahui pengaruh penentuan nilai awal metode NewtonRaphson.

\section{Metode Penelitian}

dilakukan:

$$
\text { Prosedur penelitian yang }
$$

1. Penentuan persamaan

2. Pencarian akar dengan metode Newton-Raphson
a. Penentuan nilai awal yang berbeda-beda
b. Analisis hasil dari nilai awal yang berbeda-beda

3. Pencarian akar dengan metode Newton-Raphson yang dimodifikasi

a. Penentuan nilai awal yang berbeda-beda

b. Analisis hasil dari penentuan nilai awal yang berbeda-beda

\section{Kesimpulan}

\section{Hasil dan Pembahasan}

Dalam pembahasan ini akan dilakukan proses penyelesaian persamaan linear dengan metode bisection, metode regula falsi, metode Newton Raphson dan metode Secant. Selain itu akan dibahas penyelesaian metode Newton-Raphson yang dimodifikasi dan metode Secan yang dimodifikasi. Soal yang diselesaikan merupakan soal yang memiliki akar tunggal dan akar ganda. Hasil penyelesaian akan dibandingkan.
Dalam analisis numerik, metode Newton-Raphson merupakan salah satu metode yang paling dikenal untuk mencari hampiran terhadap akar fungsi riil. Metode Newton-Raphson sering konvergen dengan cepat, terutama bila iterasi dimulai cukup dekat dengan akar yang diinginkan. Namun bila iterasi dimulai jauh dari akar yang dicari, metode ini dapat meleset tanpa peringatan. Implementasi metode ini biasanya mendeteksi dan mengatasi kegagalan konvergensi.

\section{Diketahui} dengan tebakan pertama, $x_{0}$. Hampiran yang lebih baik $x_{1}$ adalah

$f(x)=x_{0}-\frac{f\left(x_{0}\right)}{f^{\prime}\left(x_{0}\right)}$

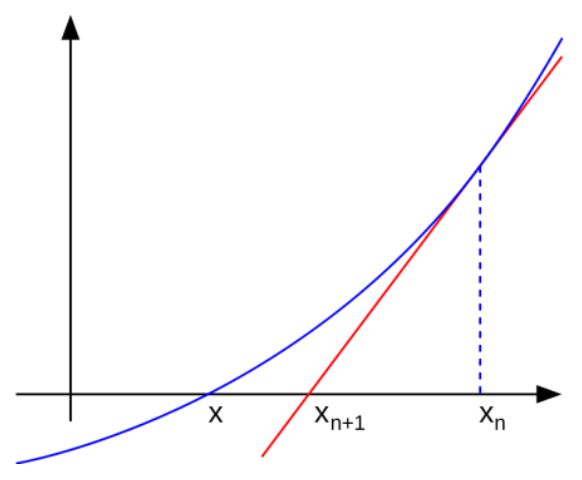

Gambar 1. Ilustrasi salah satu iterasi metode Newton (fungsi $\boldsymbol{f}$ ditunjukkan dengan warna biru dan garis singgung dalam warna merah).

Kita melihat bahwa $x_{n+1}$ adalah hampiran yang lebih baik daripada $x_{n}$ untuk akar $x$ dari fungsi $f$.

Gagasan metode NewtonRaphson adalah sebagai berikut: kita memulai dengan tebakan awal yang cukup dekat terhadap akar yang sebenarnya, kemudian fungsi tersebut dihampiri dengan garis singgungnya (yang dapat dihitung dengan alatalat kalkulus), dan kita dapat menghitung perpotongan garis ini dengan sumbu$x$ (yang dapat dilakukan dengan mudah menggunakan aljabar dasar). Perpotongan dengan sumbu- $x$ ini biasanya merupakan hampiran yang lebih baik ke akar fungsi 
daripada tebakan awal, dan metode ini dapat diiterasi.

Misalkan $f:[a, b] \rightarrow \mathbf{R}$ adalah

fungsi terturunkan yang terdefinisi pada selang $[a, b]$ dengan nilai merupakan bilangan riil R. Rumus untuk menghampiri akar dapat dengan mudah diturunkan. Misalkan kita memiliki hampiran mutakhir $x_{n}$. Maka kita dapat menurunkan hampiran yang lebih baik, $x_{n+1}$ dengan merujuk pada diagram di kanan. Kita tahu dari definisi turunan pada suatu titik bahwa itu adalah kemiringan garis singgung pada titik tersebut, yaitu:

$f^{\prime}\left(x_{n}\right)=\frac{\Delta y}{\Delta x}=\frac{f\left(x_{n}\right)-0}{x_{n}-x_{n+1}}$.......

Di sini, $f^{\prime}$ melambangkan turunan fungsi $f$. Maka dengan aljabar sederhana kita mendapatkan:

$f\left(x_{n+1}\right)=x_{n}-\frac{f\left(x_{n}\right)}{f^{\prime}\left(x_{n}\right)}$.

Kita memulai proses dengan nilai awal sembarang $x_{0}$. Metode ini biasanya akan mengerucut pada akar, dengan syarat tebakan awal cukup dekat pada akar tersebut, dan bahwa $f^{\prime}\left(x_{0}\right) \neq 0$.

Akar ganda berpadanan dengan suatu titik dimana fungsi menyinggung sumbu . Misalnya, akar ganda-dua dihasilkan dari

$f(x)=(x-3)(x-1)(x-1)$

atau dengan mengalikan faktor-faktornya, $f(x)=x^{3}-5 x^{2}+7^{x}-3$

Persamaan tersebut mempunyai akar kembar karena satu nilai menyebabkan dua faktor dalam persamaan (4) sama dengan nol. Secara grafis, ini berpadanan terhadap kurva yang yang menyentuh sumbu $\mathrm{x}$ secara bersinggungan pada akar kembar tersebut.

Akar ganda-tiga (triple root) berpadanan dengan kasus dimana satu nilai $\mathrm{x}$ membuat tiga faktor dalam suatu persamaan sama dengan nol, seperti dalam $f(x)=(x-3)(x-1)(x-1)$ atau dengan mengalikan faktor-faktornya, $f(x)=x^{4}-6 x^{3}+12 x^{2}-10 x-3$
Kesulitan yang ditimbulkan oleh akar ganda dari penerapan metode numerik.

1. Metode tertutup seperti metode bisection dan metode regulafalsi, bahwa fungsi tidak berubah tanda pada akar ganda genap.

2. Metode terbuka seperti metode Newton-Raphson kecepatan konvergensinya berjalan secara linear, tidak kuadratis sebagaimana aslinya.

3. Tidak hanya fungsi $\mathrm{f}(\mathrm{x})$ tetapi turunan pertama fungsi $\mathrm{f}(\mathrm{x})$, yakni $\mathrm{f}^{\prime}(\mathrm{x})$ menuju nol pada akar, baik metode Newton-Raphson maupun metode Secant. Kedua metode ini menggunakan turunan dalam pengembangan persamaannya. Jika $\mathrm{f}(\mathrm{x})=0$ maka iterasi dihentikan

4. Ralston dan Rabinowitz (1978) telah menjukkan bahwa menunjukan bahwa perubahan sedikit dalam perumusan mengembalikannya ke kekonvergenan kuadrat, seperti dalam

$$
x_{i+1}=x_{i}-m \frac{f\left(x_{i}\right)}{f^{\prime}\left(x_{i}\right)} \ldots \ldots \ldots \ldots \text { (5) }
$$

dengan $m$ adalah Bilangan multiplisitas akar, misalnya :

a. Akar tunggal $m=1$

b. Akar ganda dua $\mathrm{m}=2$

c. Akar ganda tiga $\mathrm{m}=3$, dan seterusnya.

Alternatif lain yang juga disarankan oleh Ralston dan Rabinowitz (1978) adalah mendefinisikan suatu fungsi baru $\mathrm{u}(\mathrm{x})$, yaitu rasio (hasil bagi) fungsi terhadap turunannya seperti dalam

$u(x)=\frac{f\left(x_{i}\right)}{f^{\prime}\left(x_{i}\right)}$

Dapat diperhatikan bahwa fungsi ini mempunyai akar pada lokasi yang sama seperti fungsi semula. Oleh karena itu, persamaan (6) di atas dapat disubtitusikan ke dalam persamaan (5) dengan maksud mengembangkan suatu 
bentuk alternatif dari metode NewtonRapshon:

$$
x_{i+1}=x_{i}-\frac{u\left(x_{i}\right)}{u^{\prime}\left(x_{i}\right)}
$$

Persamaan (6) dan (5) dapat disubtitusikan ke dalam persamaan (7) dan hasilnya disederhanakan untuk menghasilkan

$$
\begin{aligned}
& x_{i+1} \\
& =x_{i}-\frac{f\left(x_{i}\right) f^{\prime}\left(x_{i}\right)}{\left[f^{\prime}\left(x_{i}\right)\right]^{2}-f^{\prime \prime}\left(x_{i}\right) f\left(x_{i}\right)} .
\end{aligned}
$$

1. Soal pertama:

$$
\begin{aligned}
& f(x)=(x-3)(x-1)(x-1)=x^{3}-5 x^{2}+ \\
& 7 x-3 \\
& \quad \text { Secara analisis akar diperoleh }
\end{aligned}
$$
pada $\mathrm{x}=3$ dan $\mathrm{x}=1$ (akar kembar)

Dengan menggunakan metode NewtonRaphson yang dimodifikasi, persamaan yang digunakan adalah persamaan (5).

$$
\begin{aligned}
& f(x)=x^{3}-5 x^{2}+7 x-3 \\
& f^{\prime}(x)=3 x^{\wedge} 2-10 x+7 \\
& f^{\prime \prime}(x)=6 x-10
\end{aligned}
$$

Nilai awal $=0$

Tabel 1. Hasil Perhitungan Metode Newton-Raphson yang Dimodifikasi

\begin{tabular}{|c|c|c|c|c|c|c|}
\hline Iterasi & $x_{i}$ & $f\left(x_{i}\right)$ & $f^{\prime}\left(x_{i}\right)$ & $f^{\prime \prime}\left(x_{i}\right)$ & $x_{i+1}$ & $e a(\%)$ \\
\hline 1 & 0.0000 & -3.0000 & 7.0000 & -10.0000 & 1.1053 & $100 \%$ \\
\hline 2 & 1.1053 & -0.0210 & -0.3878 & -3.3684 & 1.0031 & $10.1868 \%$ \\
\hline 3 & 1.0031 & 0.0000 & -0.0123 & -3.9815 & 1.0000 & $0.3079 \%$ \\
\hline 4 & 1.0000 & 0.0000 & 0.0000 & -4.0000 & 1.0000 & $0.0002 \%$ \\
\hline 5 & 1.0000 & 0.0000 & 0.0000 & -4.0000 & 1.0000 & $0 \%$ \\
\hline
\end{tabular}

ea $=$ error aproximasi

2. Soal kedua : $\mathrm{f}(\mathrm{x})=(\mathrm{x}-3)(\mathrm{x}-1)(\mathrm{x}-$ 1) $(x-1)=x^{4}-6 x^{3}+12 x^{2}-10 x+3$

Secara analisis akar diperoleh pada $\mathrm{x}=3$ dan $\mathrm{x}=1$ (ada 3 akar kembar) Dengan menggunakan metode NewtonRaphson yang dimodifikasi, persamaan yang digunakan adalah persamaan (5).

$$
\begin{aligned}
& f(x)=x^{4}-6 x^{3}+12 x^{2}-10 x+3 \\
& f^{\prime}(x)=4 x^{3}-18 x^{2}+24 x-10 \\
& f^{\prime \prime}(x)=12 x^{2}-36 x+24
\end{aligned}
$$

Nilai awal $=0$

Tabel 2. Hasil Perhitungan Metode Newton-Raphson yang Dimodifikasi

\begin{tabular}{|l|l|l|l|l|l|l|}
\hline Iterasi & $x_{i}$ & $f\left(x_{i}\right)$ & $f^{\prime}\left(x_{i}\right)$ & $f^{\prime \prime}\left(x_{i}\right)$ & $x_{i+1}$ & $e a(\%)$ \\
\hline 1 & 0.0000 & 3.0000 & -10.0000 & 24.0000 & 1.0714 & 100.0000 \\
\hline 2 & 1.0714 & -0.0007 & -0.0292 & -0.7959 & 1.0009 & 7.0450 \\
\hline 3 & 1.0009 & 0.0000 & 0.0000 & -0.0110 & 1.0000 & 0.0914 \\
\hline 4 & 1.0000 & 0.0000 & 0.0000 & 0.0000 & 1.0000 & 0.0000 \\
\hline
\end{tabular}

ea $=$ error aproximasi

3. Soal ketiga : $f(x)=x^{3}-3 x+2$

Secara analisis akar diperoleh pada $\mathrm{x}=-2$ dan $\mathrm{x}=1$ (ada 2 akar kembar).

Dengan menggunakan persamaan (5), metode Newton-Raphson yang dimodifikasi, hasilnya sebagai berikut: $f(x)=x^{\wedge} 3-3 x+2$

$f^{\prime}(x)=3 x^{\wedge} 2-3$

$f^{\prime \prime}(\mathrm{x})=6 \mathrm{x}$

Nilai awal $=0$ 
Tabel 3. Hasil Perhitungan Metode Newton-Raphson yang Dimodifikasi untuk Persamaan $X^{\mathbf{3}}-3 x+2$

\begin{tabular}{|c|c|c|c|c|c|c|}
\hline Iterasi & $x_{i}$ & $f\left(x_{i}\right)$ & $f^{\prime}\left(x_{i}\right)$ & $f^{\prime \prime}\left(x_{i}\right)$ & $x_{i+1}$ & $e a$ \\
\hline 1 & 0.0000 & 2.0000 & -3.0000 & 0.0000 & 0.6667 & $100 \%$ \\
\hline 2 & 0.6667 & 0.2963 & -1.6667 & 4.0000 & 0.9767 & $31.7460 \%$ \\
\hline 3 & 0.9767 & 0.0016 & -0.1379 & 5.8605 & 0.9999 & $2.3166 \%$ \\
\hline 4 & 0.9999 & 0.0000 & -0.0005 & 5.9995 & 1.0000 & $0.0092 \%$ \\
\hline 5 & 1.0000 & 0.0000 & 0.0000 & 6.0000 & 1.0000 & $0 \%$ \\
\hline
\end{tabular}

Akibat pemilihan nilai awal terhadap jumlah iterasi. Iterasi berhenti sampai pada nilai kesalahan aprosimasi $\left(\mathrm{e}_{\mathrm{a}}\right)$ sama dengan $0 \%$. Perbandingan masih menggunakan tiga persamaan diatas, dengan derajat yang berbeda baik untuk akar ganda maupun untuk akar tunggal.

Tabel 4. Pengaruh Pemilihan Nilai Awal Terhadap Jumlah Iterasi Pada Metode Newton-Raphson yang Dimodifikasi untuk Akar Ganda.

\begin{tabular}{|c|c|c|c|c|c|}
\hline No & Persamaan & $\begin{array}{l}\text { Nilai } \\
\text { awal }\end{array}$ & $\begin{array}{c}\text { Selisih } \mathrm{x}_{\mathrm{i}} \text { dengan } \\
\text { nilai akar yang } \\
\text { dicari }\end{array}$ & $\begin{array}{c}\text { Jumlah iterasi } \\
\text { (berdasarkan } \\
\text { nilai ea=0ea=0) }\end{array}$ & $\begin{array}{c}\text { Akar } \\
\text { yang } \\
\text { diperoleh } \\
\end{array}$ \\
\hline \multirow[t]{4}{*}{1} & \multirow{4}{*}{$f(x)=x^{3}-5 x^{2}+7 x-3$} & -1 & 2 & 5 & 1 \\
\hline & & 0 & 1 & 4 & 1 \\
\hline & & 0.5 & 0.5 & 4 & 1 \\
\hline & & 0.75 & 0.25 & 3 & 1 \\
\hline \multirow[t]{4}{*}{2} & \multirow[t]{4}{*}{$f(x)=x^{4}-6 x^{3}+12 x^{2}-10 x+3$} & -1 & 2 & 4 & 1 \\
\hline & & 0 & 1 & 4 & 1 \\
\hline & & 0.5 & 0.5 & 3 & 1 \\
\hline & & 0.75 & 0.25 & 2 & 1 \\
\hline \multirow[t]{4}{*}{3} & \multirow[t]{4}{*}{$f(x)=x^{3}-3 x+2$} & -1 & 2 & 0 & 1 \\
\hline & & 0 & 1 & 4 & 1 \\
\hline & & 0.5 & 0.5 & 4 & 1 \\
\hline & & 0.75 & 0.25 & 3 & 1 \\
\hline
\end{tabular}

Tabel 5. Pengaruh Pemilihan Nilai Awal Terhadap Jumlah Iterasi pada Metode Newton-Raphson yang Dimodifikasi untuk Akar Tunggal.

\begin{tabular}{|c|c|c|c|c|c|}
\hline No & Persamaan & $\begin{array}{l}\text { Nilai } \\
\text { awal }\end{array}$ & $\begin{array}{c}\text { Selisih } \mathrm{x}_{\mathrm{i}} \text { dengan } \\
\text { nilai akar yang } \\
\text { dicari }\end{array}$ & $\begin{array}{c}\text { Jumlah iterasi } \\
\text { (berdasarkan } \\
\text { nilai ea }=0 \text { ) }\end{array}$ & $\begin{array}{c}\text { Akar yang } \\
\text { diperoleh }\end{array}$ \\
\hline \multirow[t]{4}{*}{1} & \multirow[t]{4}{*}{$f(x)=x^{3}-5 x^{2}+7 x-3$} & 2.75 & 0.25 & 5 & 3 \\
\hline & & 2.5 & 0.5 & 6 & 3 \\
\hline & & 4 & 1 & 7 & 3 \\
\hline & & 4.5 & 1.5 & 8 & 3 \\
\hline \multirow[t]{4}{*}{2} & \multirow[t]{4}{*}{$f(x)=x^{4}-6 x^{3}+12 x^{2}-10 x+3$} & 2.75 & 0.25 & 5 & 3 \\
\hline & & 3.5 & 0.5 & 6 & 3 \\
\hline & & 2.6 & 0.4 & 7 & 3 \\
\hline & & 3.9 & 0.9 & 8 & 3 \\
\hline \multirow[t]{4}{*}{3} & \multirow[t]{4}{*}{$f(x)=x^{3}-3 x+2$} & -3 & 1 & 6 & -2 \\
\hline & & -4 & 2 & 7 & -2 \\
\hline & & -3.5 & 1.5 & 7 & -2 \\
\hline & & -4.5 & 2.5 & 9 & -2 \\
\hline
\end{tabular}

Pi: Mathematics Education Journal 


\section{Pi:Mathematics \\ ग Education Journal}

Tabel 6. Pengaruh Penentuan Nilai Awal terhadap Jumlah Iterasi, Nilai Akar yang Diperoleh, dan Jarak Xi dengan Nilai Akar yang Diperoleh dengan Metode Newton-Raphson

\begin{tabular}{|c|c|c|c|c|c|c|}
\hline No & $\begin{array}{c}\text { Persamaan dan akar } \\
\text { sebenarnya }\end{array}$ & $\begin{array}{c}\text { Nilai } \\
\text { awal } x_{i}\end{array}$ & $\begin{array}{c}\text { Selisih dengan } \\
\text { nilai akar paling } \\
\text { dekat yang } \\
\text { dicari }\end{array}$ & $\begin{array}{l}\text { Jumlah } \\
\text { iterasi }\end{array}$ & $\begin{array}{l}\text { Akar yang } \\
\text { diperoleh }\end{array}$ & Keterangan \\
\hline \multirow[t]{10}{*}{1} & $f(x)=x^{3}-5 x^{2}+7 x-3$ & 0 & $1(=1-1)$ & 5 & 1 & \\
\hline & akar: $x_{1}=3$ & -1 & $2(=1-(-1))$ & 5 & 1 & \\
\hline & akar: $x_{2}=x_{3}=1$ & -2 & $3(=1-(-2))$ & 5 & 1 & \\
\hline & & 2 & $1(=3-1)$ & 6 & 1 & \\
\hline & & 3.5 & $0.5(=3.5-3)$ & 5 & 3 & \\
\hline & & 5.5 & $2.5(=5.5-3)$ & 9 & 1 & \\
\hline & & 7 & $4 \quad(=7-3)$ & 7 & 1 & \\
\hline & & 10 & $7 \quad(=10-3)$ & 7 & 1 & \\
\hline & & 15 & $12(=15-3)$ & 7 & 1 & \\
\hline & & 20 & $17(=20-3)$ & 6 & 1 & \\
\hline \multirow[t]{10}{*}{2} & $f(x)=x^{4}-6 x^{3}+12 x^{2}-10 x+3$ & 0 & $1(=1-1)$ & 4 & 1 & \\
\hline & $x_{1}=3$ & -1 & $2(=1-(-1))$ & 4 & 1 & \\
\hline & $\mathrm{x}_{2}=\mathrm{x}_{3}=\mathrm{x}_{4}=1$ & -2 & $3(=1-(-2))$ & 4 & 1 & \\
\hline & & 2 & $1(=3-1)$ & 5 & 1 & \\
\hline & & 3.5 & $0.5(=3.5-3)$ & 5 & 3 & \\
\hline & & 5.5 & $2.5(=5.5-3)$ & 6 & 1 & \\
\hline & & 7 & $4 \quad(=7-3)$ & 6 & 1 & \\
\hline & & 10 & $7 \quad(=10-3)$ & 5 & 1 & \\
\hline & & 15 & $12(=15-3)$ & 5 & 1 & \\
\hline & & 20 & $17(=20-3)$ & 5 & 1 & \\
\hline \multirow[t]{10}{*}{3} & $f(x)=x^{3}-3 x+2$ & -3 & $1(=-3-(-2))$ & 6 & -2 & \\
\hline & $x_{1}=-2$ & -4 & $2(=-4-(-2))$ & 7 & -2 & \\
\hline & $\mathrm{x}_{2}=\mathrm{x}_{3}=1$ & -6 & $4(=-6-(-2))$ & 8 & 1 & \\
\hline & & -10 & $8(=-10-(-2))$ & 1 & 1 & \\
\hline & & -15 & $14(=-15-(-2))$ & 7 & 1 & \\
\hline & & 0 & $1(=1-0)$ & 5 & 1 & \\
\hline & & 2 & $1(=2-1)$ & 4 & 1 & \\
\hline & & 4 & $3(=4-1)$ & 5 & 1 & \\
\hline & & 7 & $6(=7-1)$ & 5 & 1 & \\
\hline & & 10 & $9(=10-1)$ & 6 & 1 & \\
\hline
\end{tabular}

\section{Kesimpulan}

Beberapa kesimpulan yang diperoleh sebagai berikut:

1. Pengaruh pemilihan nilai awal terhadap akar yang dicari pada metode Newton-Raphson, jika nilai awal yang dipilih cukup dekat dengan nilai akar tunggal, maka dari sekian simulasi yang dilakukan hasilnya akan menampilkan akar ganda. Hal ini bisa dilihat pada persamaan pertama $f(x)=x^{3}-5 x^{2}+$ $7 \mathrm{x}-3$, yang memiliki akar tunggal di titik $\mathrm{x}_{1}=3$ dan akar dua ganda $\mathrm{x}_{2}=\mathrm{x}_{3}=1$. Demikian juga untuk persamaan kedua, $f(x)=x^{4}-$
$6 x^{3}+12 x^{2}-10 x+$, yang memiliki akar tunggal di titik $\mathrm{x}_{1}=3$ dan akar dua ganda $\mathrm{x}_{2}=\mathrm{x}_{3}=\mathrm{x}_{4}=1 . \quad($ tabel 6$)$. Tebakan awal dengan selisih 0,5 dari akar tunggal, hasilnya menampilkan akar tunggal.

2. Pemilihan nilai awal lebih dekat dengan akar tunggal dibandingkan dengan akar ganda, hasil yang ditampilkan oleh metode NewtonRaphson adalah akar ganda. Dengan demikian, sesuai dengan prinsip metode terbuka, bahwa penentuan nilai awal yang jauh dari nilai akar yang dicari, metode NewtonRaphson akan memprioritaskan

Pi: Mathematics Education Journal 
pencarian akar ganda. Hasilnya bisa dilihat pada Tabel 6 .

3. Makin jauh pemilihan nilai awal dengan akar ganda, makin besar jumlah iterasi untuk mencapoai konvergensi

\section{Daftar Rujukan}

Chapra, S. C.,Canale, R. P., 2008, Numerical Methods for Engineers - - 6th ed.p. cm. ISBN 978-0-07340106-5 - ISBN 0-07-3401064

Dey, A., 2015, Mathematical Model Formulation and Comparison Study of Various Methods of RootFinding Problems, IOSR Journal of Mathematics (IOSR-JM) e-ISSN: 2278-5728, p-ISSN: 2319-765X. Volume 11, Issue 2 Ver. III (Mar Apr. 2015), PP 64-71

Imran, M., Syamsudhuha,. Putra, S., 2016, A NEW FAMILY OF SECANT-LIKE METHOD WITH SUPER-LINEAR

CONVERGENCE, International Journal of Pure and Applied Mathematics Volume 110 No. 1 2016, 1-7 ISSN: 1311-8080 (printed version); ISSN: 1314-3395 (on-line version) url: http://www.ijpam.eu doi: 10.12732/ijpam.v110i1.1

Magrean, A.A., Argyros, I.K., 2015, EXPANDING THE APPLICABILITY OF SECANT METHOD WITH APPLICATIONS, Bull. Korean Math. Soc. 52 (2015), No. 3, pp. 865-880 http://dx.doi.org/10.4134/BKMS.20 15.52.3.865

Hussein, K.A., Altaee, A.A.H., Hoomod, H.K., 2015, Parallel Hybrid Algorithm of Bisection and Newton-RaphsoMethods to Find Non-Linear Equations Roots, IOSR Journal of Mathematics (IOSR-JM)
e-ISSN: 2278-5728, p-ISSN: 2319765X. Volume 11, Issue 4 Ver. II (Jul - Aug. 2015), PP 32-36

Ehiwario, J.C., Aghamie, S.O., 2014, Comparative Study of Bisection, Newton-Raphson and Secant Methods of Root- Finding Problems, IOSR Journal of Engineering (IOSRJEN) ISSN (e): 2250-3021, ISSN (p): 2278-8719. Vol. 04, Issue 04 (April. 2014), ||V1|| PP 01-07

Ahmad, A. G., 2015, Comparative Study of Bisection and Newton-Rhapson Methods of Root-Finding Problems , International Journal of Mathematics Trends and Technology- Volume 19 Number 2 Mar 2015.

Kumar, R., Vipan, 2015, Comparative Analysis of Convergence of Various Numerical Methods, Journal of Computer and Mathematical Sciences, Vol.6(6),290-297, June 2015 ISSN 0976-5727 (Print), ISSN 2319-8133 (Online),(An International Research Journal), www.compmathjournal.org

Sharma,S.K., 2017, A Comparative Analysis of Rate of Convergence For Linear And Quadratic Approximations in N-R Method , World Journal of Research and Review (WJRR) ISSN:2455-3956, Volume-4, Issue-5, May 2017 Pages 94-96

Mohammad, H., 2015, A Simple Hybrid Method for Finding the Root of Nonlinear Equations IJSRST | Volume 1 | Issue 4 | Print ISSN: 2395-6011 | Online ISSN: 2395602X IJSRST151420 | Received: 09 October 2015 | Accepted: 16 October 2015 | September-October 2015 [(1)4: 80-83] 
Torres, F.G., 2015, to Achieve Convergence of Order 1+v2 and Its Dynamics A Novel Geometric Modification to the Newton-Secant Method, Hindawi Publishing Corporation Modelling and Simulation in Engineering Volume 2015, Article ID 502854, 6 pages http://dx.doi.org/10.1155/2015/5028 54 